Statistica Neerlandica (2009) Vol. 63, nr. 3, pp. 368-384

doi:10.1111/j.1467-9574.2009.00429.x

\title{
Testing non-nested demand relations: linear expenditure system versus indirect addilog*
}

\author{
Paul de Boer† and Richard Paap \\ Econometric Institute, Erasmus University Rotterdam
}

In applied economic research computable general equilibrium (CGE) models in which the behavior of economic agents are modeled, are widely used. In many CGE models, the linear expenditure system (LES) is used to model the behavior of the household sector. The disadvantage of LES is that the Engel curves, describing the relationship between expenditure on a certain commodity and total expenditure, are straight lines. Moreover, the LES does not allow for the existence of inferior commodities, elastic demand and gross substitution. An alternative model for the household block is the indirect addilog system (IAS), which is as simple to implement as LES, but which does not suffer from these theoretical deficiencies. In this paper, we test the LES specification against the IAS specification in case one disposes of a budget survey. Consequently, IAS provides a theoretically richer description of household behavior than LES, while it is also easy to implement.

It is not possible to use a standard likelihood ratio test as both models are not nested. We propose to use the likelihood ratio test for nonnested hypotheses due to Vuong [(1989), Likelihood ratio tests for model selection and non-nested hypotheses, Econometrica 57, 307333.] or, alternatively, the distribution-free test due to Clarke [(2007), A simple distribution-free test for nonnested model selection, Political Analysis 15, 347-363.]. We apply both tests to the Palestinian Expenditure and Consumption Survey [PECS (2005), Palestinian Central Bureau of Statistics, Ramallah, Palestine.] and find that there is overwhelming evidence that the IAS specification is to be preferred to the LES specification.

Keywords and Phrases: models of household behavior, non-nested hypothesis testing.

*Calculations in this paper are performed in Gauss 6.0. See 'Gauss program' in Appendix C. This paper is dedicated to Prof. W. H. Somermeyer, Director of the Econometric Institute from 1966 until his untimely death on 31 May 1982. Wim Somermeyer was friend and guide to author Paul de Boer, as well as supervisor of his $\mathrm{PhD}$ thesis.

†pmdeboer@ese.eur.nl

tpaap@ese.eur.nl

(C) 2009 The Authors. Journal compilation (c) 2009 VVS.

Published by Blackwell Publishing, 9600 Garsington Road, Oxford OX4 2DQ, UK and 350 Main Street, Malden, MA 02148, USA. 


\section{Introduction}

In applied economic research, computable general equilibrium (CGE) models are widely used. In these models, the behavior of several economic actors (e.g. firms, households, government, rest of the world) is modeled in blocks, the links between these blocks are modeled, as well.

The CPB Netherlands Bureau for Economic Policy Analysis uses a recursively dynamic CGE model for the world economy, called as WorldScan. For a technical description of this model we refer to LeJour et al. (2006). ${ }^{1}$ The model is used both as a tool to construct long-term scenarios and as an instrument for policy assessments. Recently, it has been used in the fields of economic integration (DE BRUIJN, Kox and Lejour, 2008; Lejour, Rojas-Romagosa and Verweij, 2008) and climate change (VeEnendaAl and Manders, 2008). For a description of the various models used by the CPB Netherlands Bureau of Economic Policy Research we refer to DoN and Verbruggen (2006).

In this paper we focus on one of these blocks, the household model. We quote LEJOUR et al. (2006, p. 65):

On the basis of the preferences consumers decide how to spend their budget on consumer goods and services. The Linear Expenditure System [LES] is suitable to model this consumption decision, because it combines simplicity with some flexibility. (...). The modeling of consumer choice is also important as it enables explicit welfare analyses.

It follows that in WorldScan, linear expenditure system (LES) is adopted for modeling the household block. The explicit welfare indexes that are commonly adopted to measure the impact of changes in economic policy are the so-called 'equivalent variation' and/or 'compensating variation' (VARIAN, 1992). The outcome of these indexes depends on the choice of the household model.

Besides WorldScan, other well-known CGE models use LES specifications, as well. MIRAGE, the CGE model of CEPII (Centre d'Études Prospectives et d'Informations Internationales) uses a combination of the constant elasticities of substitution (CES) functional form (ARrow et al., 1961) combined with LES (BCHIR et al., 2002, p. 47). Linkage, a CGE model of the World Bank, uses as default the LES augmented with savings (VAn DER Mensbrugghe, 2005, p. 21). GTAP (the Global Trade Analysis Project of the Purdue University), besides LES, allows for a generalization of LES, the so-called AIDADS (An Implicitly Directly Additive Demand System) (Cranfield et al., 2000; Reimer and Hertel, 2004). This model, an implicit additive demand system, is due to Rimmer and Powell (1996). VAn Der Mensbrugghe (2005) discusses this model in his appendix G. AIDADS allows for a richer description of Engel curves (the relationship between expenditure on a certain commodity, good or service, and total expenditure) than LES, but 'comes at the expense of an additional $(J-1)$ parameters' (RIMMER and Powell, 1996, p. 1615). In many practical applications, this prevents AIDADS from being used. ${ }^{2}$

The disadvantage of LES is that the Engel curves are straight lines. Moreover, the LES does not allow for the existence of inferior commodities (income elastic(c) 2009 The Authors. Journal compilation () 2009 VVS. 
ities smaller than zero), elastic demand (absolute value of the own price elasticity larger than one) and gross substitution (negative cross-price elasticity); see CHUNG (1994, chap. 2). An alternative model for the household block is the indirect addilog system (IAS), which is as simple to implement as LES, but which exhibits non-linear Engel curves and allows for the existence of inferior commodities, elastic demand and gross substitution. Consequently, IAS provides for a theoretically richer description of household behavior than LES, while it is also easy to implement.

The purpose of this paper is to test the LES specification against the IAS specification when both models are estimated using budget survey data. As both models are not nested, it is not possible to use a standard likelihood ratio test. To compare both specifications, we first express the log-likelihood functions of both models in terms of a density for the demands for the commodities. Next, we propose to use the likelihood ratio test for non-nested hypotheses of Vuong (1989), or, alternatively, the distribution-free test due to ClaRKE (2007) for a formal statistical comparison.

The outline of this paper is as follows. In section 2, we present the economic theoretical background of these two systems of demand relations. Section 3 deals with parameter estimation and the derivation of the test statistics using the approach of Vuong and of Clarke. As this dataset is readily available, we apply, in section 4, both tests to the Palestinian Expenditure and Consumption Survey (PECS, 2005). It turns out that there is overwhelming evidence for IAS specification over the LES specification. Section 5, finally, contains some concluding remarks.

\section{The two systems of demand relations}

In an economy there are $J$ commodities with prices $p_{j}(j=1, \ldots, J)$, which are given for a household. Let $p$ denote the (row) vector with typical element $p_{j}$. Given its budget $m$ (income minus savings), the household has to decide on the quantity $\left(y_{j}\right)$ to be purchased from each commodity $(j)$. Let $y$ denote the (row) vector with typical element $y_{j}(j=1, \ldots, J)$. The decision is based on the maximization of its direct utility function $U(y)=f(y)$. Let the solution of this constrained optimization problem be denoted by $y_{j}=g_{j}(p, m)$. Substitution of this solution into the utility function yields the so-called indirect utility function $V(p, m)=f\left(g_{1}(p, m), \ldots, g_{J}(p, m)\right)$. Applying the implicit function theorem to the indirect utility function (in the framework of the theory of household demand called Roy's identity) yields the demand for commodity $j$ :

$$
y_{j}(p, m)=-\frac{\partial V(p, m) / \partial p_{j}}{\partial V(p, m) / \partial m} .
$$

\subsection{The LES}

Tinbergen (1942) proposed to generalize the Cobb-Douglas production function (Совв and Douglas, 1928) by introducing positive minimum amounts of capital and () 2009 The Authors. Journal compilation (๔ 2009 VVS. 
labor. Shortly after the Second World War, this idea was introduced in the theory of household behavior in a series of articles: KLeIN and Rubin (1948-1949), SAMuelson (1948), Geary (1949-1950) and Stone (1954). This function is known as the Stone-Geary utility function and the ensuing demand model as the LES. It is based on the maximization of the direct utility function:

$$
U(y)= \begin{cases}\prod_{j=1}^{J}\left(y_{j}-\mu_{j}\right)^{\alpha_{j}} & \text { if } y_{j}>\mu_{j} \\ 0 & \text { if } y_{j} \leq \mu_{j},\end{cases}
$$

with parameters: $\alpha_{j}>0$ (called marginal budget shares), and $\mu_{j} \geq 0$ (subsistence quantities).

Because utility is ordinal, any monotonous transformation of the utility function is a utility function as well. Therefore, without any loss of generality we impose the restriction:

$$
\sum_{j=1}^{J} \alpha_{j}=1 .
$$

The household maximizes its utility function (2) subject to its budget constraint:

$$
\sum_{j=1}^{J} p_{j} y_{j}=m .
$$

The demand relations easily follow and read:

$$
y_{j}=\mu_{j}+\alpha_{j} p_{j}^{-1}\left(m-\sum_{k=1}^{J} p_{k} \mu_{k}\right)
$$

so that the Engel curve, the relationship between expenditure on commodity $j\left(p_{j} y_{j}\right)$ and its budget $m$, is a linear function:

$$
p_{j} y_{j}=p_{j} \mu_{j}+\alpha_{j}\left(m-\sum_{k=1}^{J} p_{k} \mu_{k}\right) .
$$

Because $\mu_{k}$ is interpreted to be the minimum quantity demanded of commodity $k$, $\Sigma_{k=1}^{J} p_{k} \mu_{k}$ represents the subsistence expenditure of the household and $\left(m-\Sigma_{k=1}^{J} p_{k} \mu_{k}\right)$ is called its supernumerary or discretionary expenditure. According to this model, the household purchases first the minimum quantities of each commodity, and second, allocates its discretionary expenditure in fixed fractions over the commodities.

Defining the budget shares:

$$
w_{j}=\frac{p_{j} y_{j}}{m} \quad \text { for } j=1, \ldots, J
$$

the income elasticity (which measures the percentage change in the demand for a commodity $y_{j}$ given a $1 \%$ change in the household's budget $m$ ) is easily derived from Equation (5): 


$$
E\left(y_{j}, m\right)=\frac{\partial \ln y_{j}}{\partial \ln m}=\frac{\alpha_{j}}{w_{j}} \quad \text { for } j=1, \ldots, J .
$$

We assume that each household in the budget survey faces the same utility function. Moreover, prices are not recorded, so that it is assumed that all households face the same price. Without loss of generality all prices are put equal to one. Introducing the index $i$ to denote the respondent $(i=1, \ldots, N$, where $N$ denotes the number of respondents), and an additive disturbance $\varepsilon_{i j}$, the LES [Equation (5)] boils down to:

$$
y_{i j}=\mu_{j}+\alpha_{j}\left(m_{i}-\sum_{k=1}^{J} \mu_{k}\right)+\varepsilon_{i j}=\gamma_{j}+\alpha_{j} m_{i}+\varepsilon_{i j},
$$

where

$$
\gamma_{j}=\mu_{j}-\alpha_{j} \sum_{k=1}^{J} \mu_{k}
$$

Because of the adding-up restriction (3), it follows from Equation (10) that $\Sigma_{j=1}^{J} \gamma_{j}=0$. Consequently, the parameters $\mu_{j}$ are not identified (in Appendix A, we shortly describe how they are usually identified in CGE-modeling). Moreover, summation of Equation (9) over $j$ implies, taking account of Equations (3) and (4) (with all prices put equal to one), that $\Sigma_{j=1}^{J} \varepsilon_{i j}=0$ for all $i$. Consequently, the covariance matrix of the disturbances is singular. This problem is solved by deleting an arbitrary demand relation from the system, without loss of generality to the first one.

\subsection{The IAS}

The IAS has been introduced by LESER (1941) and, independently, by SoMERMEYER and WiT (1956) by directly specifying the functional form. HouthaKKer (1960) derived the system by applying Roy's identity (1) to the indirect addilog utility function: ${ }^{3}$

$$
v(p, m)=\sum_{j=1}^{J} c_{j} \frac{\left(m / p_{j}\right)^{\beta_{j}}-1}{\beta_{j}}
$$

The budget share equations ${ }^{4}$ of IAS are:

$$
w_{j}=\frac{c_{j}\left(m / p_{j}\right)^{\beta_{j}}}{\sum_{k=1}^{J} c_{k}\left(m / p_{k}\right)^{\beta_{k}}} .
$$

In the literature, there is confusion about the restrictions to be imposed on the parameters. ${ }^{5}$ MURTY (1982), without proof, gives the correct restrictions:

$$
c_{j} \geq 0 \quad \text { and } \quad \beta_{j} \geq-1
$$


for all $j$, the equality holding for at most $J-1$ commodities in the first case and at most for one commodity in the second case. The proof has been supplied by De Boer et al. (2006).

The parameters $c_{j}$, called 'preference coefficients', are indeterminate, i.e. to say: if we multiply each of them by the same factor, Equation (12) does not change. Therefore, we impose the identifying restriction that the preference coefficients sum up to one:

$$
\sum_{j=1}^{J} c_{j}=1
$$

From Equation (12) we derive the Engel curve:

$$
p_{j} y_{j}=\left(\frac{c_{j}\left(m / p_{j}\right)^{\beta_{j}}}{\sum_{k=1}^{J} c_{k}\left(m / p_{k}\right)^{\beta_{k}}}\right) \times m .
$$

Because the first term in Equation (15) is a non-linear function in $m$, the Engel curve is non-linear. It can easily be shown (Somermeyer and Langhout, 1972) that the income elasticities are:

$$
E\left(y_{j}, m\right)=\frac{\partial \ln y_{j}}{\partial \ln m}=1+\beta_{j}-\sum_{k=1}^{J} w_{k} \beta_{k} .
$$

Like we did for LES, we put all prices equal to one and introduce the index $i$ to denote the respondent $(i=1, \ldots, N)$. Then, IAS [Equation (12)] boils down to:

$$
w_{i j}=\frac{y_{i j}}{\sum_{k=1}^{J} y_{i k}}=\frac{c_{j} m_{i}^{\beta_{j}}}{\sum_{k=1}^{J} c_{k} m_{i}^{\beta_{k}}} .
$$

Selecting a reference commodity, without loss of generality commodity 1 , it easily follows, after introducing an additive disturbance, that:

$$
\tilde{y}_{i j}=\ln \left(\frac{y_{i j}}{y_{i 1}}\right)=\delta_{j}+\left(\beta_{j}-\beta_{1}\right) \ln m_{i}+\varepsilon_{i j} \quad \text { for } j=2, \ldots, J
$$

with

$$
\delta_{j}=\ln c_{j}-\ln c_{1} .
$$

By taking the logarithm of the ratio of the demand for a commodity $j(=2, \ldots, J)$ and the demand for the reference commodity 1 we circumvent the singularity problem of the covariance matrix of the disturbances. It follows from Equations (18) and (19) that the reaction coefficients $\beta_{j}$ and the preference coefficients $c_{j}$ are not identified (in Appendix A, we propose a method of identification of the parameters).

Having estimated the differences of the parameters of interest, we obtain the estimates of the income elasticities by rewriting Equation (16) to:

$$
E\left(y_{j}, m\right)=1+\beta_{j}-\sum_{k=1}^{J} w_{k} \beta_{k}=1+\left(\beta_{j}-\beta_{1}\right)-\sum_{k=1}^{J} w_{k}\left(\beta_{k}-\beta_{1}\right) .
$$




\section{Parameter estimation and testing}

In section 3.1, we discuss estimation of the parameters of the IAS and LES specifications. The tests to compare both the specifications are discussed in section 3.2.

\subsection{Parameter estimation}

To estimate the parameters of the LES we consider the multivariate regression model (9) written in vector notation

$$
y_{i}=\Pi x_{i}+\varepsilon_{i}
$$

for $i=1, \ldots, N$, where $y_{i}$ is a $(J-1)$-dimensional vector containing the demands for the last $J-1$ commodities $\left(y_{i 2}, \ldots, y_{i J}\right), x_{i}$ is a two-dimensional vector containing an intercept and the budget restriction $m_{i}$. The $(J-1) \times 2$ matrix $\Pi$ contains the $J-1$ intercept parameters and the $J-1$ marginal budget shares. We assume that the $(J-1)$-dimensional error term $\varepsilon_{i}=\left(\varepsilon_{i 2}, \ldots, \varepsilon_{i J}\right)^{\prime}$ is normally distributed with mean zero and $(J-1) \times(J-1)$-dimensional covariance matrix $\Sigma$.

The log-likelihood function belonging to this multivariate regression model is given by

$$
\begin{aligned}
\ell_{\mathrm{LES}}(y \mid \Pi, \Sigma) & =\sum_{i=1}^{N} \ln f_{\mathrm{L} E S}\left(y_{i} \mid \Pi, \Sigma\right) \\
& =\sum_{i=1}^{N}\left(-\frac{J-1}{2} \ln 2 \pi-\frac{1}{2} \ln |\Sigma|-\frac{1}{2}\left(y_{i}-\Pi x_{i}\right)^{\prime} \Sigma^{-1}\left(y_{i}-\Pi x_{i}\right)\right) .
\end{aligned}
$$

As the multivariate regression model contains the same regressors in all equations, the maximum likelihood (ML) estimates of the parameters in $\Pi$ are equal to the ordinary least squares (OLS) estimates in Equation (9). The ML estimate of $\Sigma$ is equal to $\frac{1}{N} \Sigma_{i=1}^{N} \hat{\varepsilon}_{i} \hat{\varepsilon}_{i}^{\prime}$, where $\hat{\varepsilon}_{i}$ denotes the vector of OLS residuals.

To estimate the parameters of the IAS, we consider the multivariate regression model (18) in vector notation

$$
\tilde{y}_{i}=\tilde{\Pi} \tilde{x}_{i}+\tilde{\varepsilon}_{i}
$$

for $i=1, \ldots, N$ with $\tilde{\varepsilon}_{i} \sim N(0, \tilde{\Sigma})$, where $\tilde{y}_{i}$ is a $(J-1)$-dimensional vector containing the log demands of the last $J-1$ commodities in deviation from the log demand of commodity $1\left(\ln \left(y_{i 2}\right)-\ln \left(y_{i 1}\right), \ldots, \ln \left(y_{i J}\right)-\ln \left(y_{i 1}\right)\right)^{\prime}$. The vector $\tilde{x}_{i}$ contains an intercept and the $\log$ budget restriction $\ln m_{i}$. The $(J-1) \times 2$ matrix $\tilde{\Pi}$ contains the $J-1$ intercept parameters and the $J-1$ differences of reaction coeffcients $\left(\beta_{j}-\beta_{1}\right)$. $\tilde{\Sigma}$ is the $(J-1) \times(J-1)$-dimensional covariance matrix of the $(J-1)$-dimensional error term $\tilde{\varepsilon}_{i}=\left(\tilde{\varepsilon}_{i 2}, \ldots, \tilde{\varepsilon}_{i J}\right)^{\prime}$. 
The log-likelihood function belonging to this multivariate regression model is given by

$$
\begin{aligned}
\ell_{\mathrm{I} A S}(\tilde{y} \mid \tilde{\Pi}, \tilde{\Sigma}) & =\sum_{i=1}^{N} \ln f_{\mathrm{I} A S}\left(\tilde{y}_{i} \mid \tilde{\Pi}, \tilde{\Sigma}\right) \\
& =\sum_{i=1}^{N}\left(-\frac{J-1}{2} \ln 2 \pi-\frac{1}{2} \ln |\tilde{\Sigma}|-\frac{1}{2}\left(\tilde{y}_{i}-\tilde{\Pi} \tilde{x}_{i}\right)^{\prime} \tilde{\Sigma}^{-1}\left(\tilde{y}_{i}-\tilde{\Pi} \tilde{x}_{i}\right)\right)
\end{aligned}
$$

The ML estimate of $\tilde{\Pi}$ contains the OLS estimates in Equation (18) and $\tilde{\Sigma}$ can be estimated using the OLS residuals in the same way as for the LES specification.

It is not possible to compare the values of the log-likelihood functions directly as for the LES specification the likelihood function is expressed in terms of the density of $y$, while for the IAS specification we consider the density of $\tilde{y}$. To make the likelihood function of the LES and IAS comparable, we consider the log-likelihood function of the IAS as a density of $y$, i.e. $\ell_{\mathrm{I} A S}(y \mid \tilde{\Pi}, \tilde{\Sigma})=\sum_{i=1}^{N} \ln f_{\mathrm{I} A S}\left(y_{i} \mid \tilde{\Pi}, \tilde{\Sigma}\right)$. The log-likelihood contributions of this likelihood are given by

$$
\ln f_{\mathrm{I} A S}\left(y_{i} \mid \tilde{\Pi}, \tilde{\Sigma}\right)=\ln f_{\mathrm{I} A S}\left(\tilde{y}_{i} \mid \tilde{\Pi}, \tilde{\Sigma}\right)+\ln \left|\frac{\partial \tilde{y}_{i}}{\partial y_{i}}\right|,
$$

where the last term is the log of the Jacobian of the transformation from $\tilde{y}_{i}$ to $y_{i}$. This Jacobian equals

$$
\left|\frac{\partial \tilde{y}_{i}}{\partial y_{i}}\right|=\left|\frac{\sum_{j=1}^{J} y_{i}}{\prod_{j=1}^{J} y_{i}}\right|
$$

see Appendix B for the derivation.

\subsection{Testing}

Although we now can compare the likelihood values of both specifications, it is not possible to test the LES specification against the IAS specification using a standard likelihood ratio test as both models are not nested. To test both specifications against each other, we use the approach of VuOng (1989) and Clarke (2007).

VuONG (1989) considers the null hypothesis

$$
H_{0}: \mathrm{E}_{0}\left[\ln \left(\frac{f_{\mathrm{I} A S}\left(y_{i} \mid \tilde{\Pi}, \tilde{\Sigma}\right)}{f_{\mathrm{L} E S}\left(y_{i} \mid \Pi, \Sigma\right)}\right)\right]=0
$$

which corresponds to the hypothesis that two models are equally close to the true specification. The test statistic boils down to

$$
\frac{\ell_{\mathrm{I} A S}(y \mid \hat{\tilde{\Pi}}, \hat{\tilde{\Sigma}})-\ell_{\mathrm{L} E S}(y \mid \hat{\Pi}, \hat{\Sigma})}{\sqrt{N} \hat{\omega}_{N}},
$$


where $\hat{\Pi}, \hat{\Sigma}$ and $\hat{\tilde{\Pi}}, \hat{\tilde{\Sigma}}$ are the ML estimates of the parameters of the LES and IAS, respectively, and where

$$
\hat{\omega}_{N}^{2}=\frac{1}{N} \sum_{i=1}^{N} \ln \left(\frac{f_{\mathrm{I} A S}\left(y_{i} \mid \hat{\tilde{\Pi}}, \hat{\tilde{\Sigma}}\right)}{f_{\mathrm{LES}}\left(y_{i} \mid \hat{\Pi}, \hat{\Sigma}\right)}\right)^{2}-\left(\frac{1}{N} \sum_{i=1}^{N} \ln \left(\frac{f_{\mathrm{I} A S}\left(y_{i} \mid \hat{\tilde{\Pi}}, \hat{\tilde{\Sigma}}\right)}{f_{\mathrm{LES}}\left(y_{i} \mid \hat{\Pi}, \hat{\Sigma}\right)}\right)\right)^{2} .
$$

The test statistic is asymptotically standard and normally distributed under the null hypothesis. Note that both models have the same number of parameters and hence no degrees of freedom correction is necessary.

Clarke (2007) proposes a distribution-free test and considers the null hypothesis

$$
H_{0}: \operatorname{Pr}_{0}\left[\ln \left(\frac{f_{\mathrm{I} A S}\left(y_{i} \mid \tilde{\Pi}, \tilde{\Sigma}\right)}{f_{\mathrm{LES}}\left(y_{i} \mid \Pi, \Sigma\right)}\right)>0\right]=0.5
$$

The test statistics is simply the number of times that $\ln f_{\mathrm{I} A S}\left(y_{i} \mid \hat{\tilde{\Pi}}, \hat{\tilde{\Sigma}}\right)$ is larger than $\ln f_{\mathrm{LES}}\left(y_{i} \mid \hat{\Pi}, \hat{\Sigma}\right)$. The test statistics is under the null hypothesis $\operatorname{Bin}(N, 0.5)$ distributed.

Note that to compare the log-likelihood functions of both models we have expressed the density of the IAS in levels $y$ using the Jacobian transformation. Another possibility is to express the log-likelihood function of the LES in terms of $\tilde{y}$. This does however not lead to a different value of the test statistics as $\ln f_{\mathrm{LES}}\left(\tilde{y}_{i} \mid \Pi, \Sigma\right)=$ $\ln f_{\mathrm{L} E S}\left(y_{i} \mid \Pi, \Sigma\right)+\ln \left|\partial y_{i} / \partial \tilde{y}_{i}\right|$ and $\ln \left|\partial y_{i} / \partial \tilde{y}_{i}\right|=-\ln \left|\partial \tilde{y}_{i} / \partial y_{i}\right|$. Furthermore, given the fact that the value of the likelihood function and the Jacobian of the transformation are independent of the chosen reference commodity the values of the test statistics also do not depend on the choice of the reference commodity.

In the next section, we will illustrate the use of the Vuong and Clarke tests on the PECS (2005).

\section{Application}

To illustrate the use of the Vuong (1989) and Clarke (2007) tests, we estimate demand relations for the PECS (2005). We consider ten sectors, i.e. expenditures on food, beverages, clothing, housing, furniture, recreation, education, transport, medical expenditures and a miscellaneous category. We have observations on total expenditures and expenditures in the ten sectors for $N=2152$ individuals.

We estimate the parameters of an LES and an IAS following the approach in section 3. The average log-likelihood contribution of the LES is -65.364 , while for the IAS we obtain -52.567 (in levels). The values of the log-likelihood functions of both models suggest that the IAS is better than the LES. To analyze whether this difference is statistically significant, we consider the Vuong and Clarke tests discussed in section 3.2. The value of the Vuong test statistic equals 31.033 and hence we reject the null that both specifications are equally close to the true specification versus the alternative that IAS is closer ( $P$-value is 0.000$)$. If we apply the Clarke (c) 2009 The Authors. Journal compilation (c) 2009 VVS. 
Table 1. Parameter estimates and elasticities with estimated standard error for the indirect addilog system

\begin{tabular}{|c|c|c|c|c|c|c|}
\hline \multirow[b]{2}{*}{ Commodity } & \multicolumn{2}{|l|}{ Intercept } & \multicolumn{2}{|l|}{$\beta_{j}-\beta_{1}$} & \multicolumn{2}{|c|}{ Elasticity* } \\
\hline & Estimate & SE & Estimate & SE & Estimate & SE \\
\hline Food & - & - & 0 & - & 0.493 & 0.018 \\
\hline Beverages & -9.072 & 0.514 & 0.819 & 0.063 & 1.312 & 0.064 \\
\hline Clothing & -18.907 & 0.926 & 1.920 & 0.114 & 2.413 & 0.113 \\
\hline Housing & 1.506 & 0.177 & -0.219 & 0.022 & 0.274 & 0.025 \\
\hline Furniture & -9.113 & 0.447 & 0.834 & 0.055 & 1.327 & 0.054 \\
\hline Medical & -11.359 & 1.081 & 0.808 & 0.133 & 1.301 & 0.133 \\
\hline Transport & -11.233 & 0.461 & 1.199 & 0.057 & 1.692 & 0.055 \\
\hline Recreation & -20.892 & 0.973 & 1.941 & 0.120 & 2.434 & 0.117 \\
\hline Education & -18.736 & 1.004 & 1.667 & 0.124 & 2.160 & 0.124 \\
\hline Miscellaneous & -8.914 & 0.508 & 0.800 & 0.063 & 1.293 & 0.061 \\
\hline
\end{tabular}

Note: *Elasticities are given in Equation (20), where $w_{j}$ is set equal to the total budget share in the sample.

test, we find that in $91 \%$ of the cases the log-likelihood contributions of the IAS specification are larger than the log-likelihood contributions of the LES specification ( $P$-value based on a binomial distribution with $N=2152$ and $p=0.5$ is 0.000 ). Hence, the Clarke test also indicates that the IAS is significantly closer to the true specification.

Table 1 provides the parameter estimates and the estimated elasticities of the IAS. The elasticities are computed using Equation (20), where $w_{j}$ is set equal to the total budget share of the commodities in the sample. It follows that the expenditure elasticities of food and of housing are lower than one, which means that these are necessary commodities. This confirms the famous law of EngEL (1857) that food is necessary and the less known law of Schwabe (1868) that housing is a necessary commodity, as well. The other major groups turn out to be luxury commodities, as their expenditure elasticity is larger than one.

\section{Conclusion}

In this paper, we have considered the LES and IAS specifications to model the behavior of the household sector. The parameters of both specifications are estimated using budget survey information. As both specifications are non-nested, we have proposed to use the likelihood ratio-based tests of VuONG (1989) and Clarke (2007) for non-nested hypotheses. To illustrate our approach, we have applied both tests to the PECS (2005) and find that there is overwhelming evidence for the IAS specification over the LES specification.

Our test statistic is based on the normality assumption of the disturbances in the multivariate regression equations that are needed to estimate the LES and IAS specifications. One can easily relax this assumption by assuming a finite mixture of multivariate normals for the distribution of the disturbances. It is well known that this mixture specification can approximate many types of multivariate distributions. The mixture of multivariate normal specification can also be used to account for () 2009 The Authors. Journal compilation (c) 2009 VVS. 
potential heteroskedasticity in the disturbances across individuals. We consider these extensions as topic for future research.

\section{Appendix A: Calibration of parameters}

\section{A. 1 Linear expenditure system}

The minimum subsistence levels $\mu_{j}$ are not identified. In CGE modeling, one usually assigns a value to the expenditure elasticity of the marginal utility of income $(\lambda)$, the so-called Frisch parameter $\varphi_{m}$. In the framework of LES, it is equal to minus the inverse of the fraction of supernumerary expenditure in total expenditure (BLONIGEN, FLYNN and REINERT, 1997):

$$
\varphi_{m}=\frac{\partial \log \lambda}{\partial \log m}=-\frac{m}{\left(m-\sum_{k=1}^{J} p_{k} \mu_{k}\right)} .
$$

Substituting this expression in Equation (5), putting the price equal to 1, we arrive, after rewriting, at:

$$
\mu_{j}=y_{j}+\alpha_{j} m \varphi_{m}^{-1},
$$

where $y_{j}$ is the average expenditure on commodity $j$ in the budget survey, and $m$ denotes the average total expenditure in the budget survey.

To clarify the procedure, suppose that a consumer commits $20 \%$ of its expenditure to the purchase of its subsistence expenditure. Then, its Frisch parameter is equal to $-1 / 0.80=-1.25$.

\section{A.2 Indirect addilog system}

The reaction coefficients $\beta_{j}$ are not identified. One might, like in the case of the LES assign a value to the Frisch parameter. ${ }^{6}$ However, in the framework of IAS it does not have a clear link to an economic concept as in the case of LES. Alternatively, one may fix a value of one of the price elasticities. Suppose for instance that it is reasonable to fix the own price elasticity of the reference commodity food at -0.8 . This means that if the price of food increases by $1 \%$ the demand for food decreases by $0.8 \%$. It can be derived from Equation (12) that the own price elasticity of food is equal to:

$$
E\left(y_{1}, p_{1}\right)=-\left(1-w_{1}\right) \beta_{1}-1,
$$

see Somermeyer and Langhout (1972).

As $w_{1}$, the average budget share of food, is known from the survey, fixing the own price elasticity at -0.8 yields the calibrated value of $\beta_{1}$. The calibrated value of the other reaction coefficients follow from Table 1. Putting prices equal to one, taking the identifying restriction [Equation (14)] into account, we can use Equation (12) to calibrate the preference coefficients $c_{j}$ : 


$$
c_{j}=\frac{y_{j} m^{-\beta_{j}}}{\sum_{k=1}^{J} y_{k} m^{-\beta_{k}}} .
$$

\section{Appendix B: Derivation of the Jacobian}

To derive the Jacobian, we use that $\ln \left(\tilde{y}_{i j}\right)=\ln \left(y_{i j}\right)-\ln \left(m_{i}-\Sigma_{j=2}^{J} y_{i j}\right)$. Hence,

$$
\begin{aligned}
\left|\frac{\partial \tilde{y}_{i}}{\partial y_{i}}\right| & =\left|\left(\begin{array}{ccccc}
1 / y_{i 2}+1 / y_{i 1} & 1 / y_{i 1} & \ldots & 1 / y_{i 1} & 1 / y_{i 1} \\
1 / y_{i 1} & 1 / y_{i 3}+1 / y_{i 1} & 1 / y_{i 1} & \ldots & 1 / y_{i 1} \\
\vdots & 1 / y_{i 1} & \ddots & 1 / y_{i 1} & \vdots \\
1 / y_{i 1} & \vdots & 1 / y_{i 1} & 1 / y_{i J-1}+1 / y_{i 1} & 1 / y_{i 1} \\
1 / y_{i 1} & 1 / y_{i 1} & \ldots & 1 / y_{i 1} & 1 / y_{i J}+1 / y_{i 1}
\end{array}\right)\right| \\
& =\left|\operatorname{diag}\left(1 / y_{i 2}+1 / y_{i 1}, \ldots, 1 / y_{i J}+1 / y_{i 1}\right)+1 / y_{i 1} l_{J-1} l_{J-1}^{\prime}\right|,
\end{aligned}
$$

where $l_{J-1}$ is a $(J-1)$-dimensional vector of ones. If we use that for a non-singular diagonal $(J-1) \times(J-1)$-dimensional matrix $D$, a scalar $\alpha$ and a $(J-1)$-dimensional vector $d$ it holds that $\left|D+\alpha d d^{\prime}\right|=|D|\left|1+\alpha d^{\prime} D^{-1} d\right|$ (DHRYMEs, 1978, proposition 1 ), it is easy to show that

$$
\left|\frac{\partial \tilde{y}_{i}}{\partial y_{i}}\right|=\left|\prod_{j=2}^{J} \frac{1}{y_{i j}}\left(1+\frac{\sum_{j=2}^{J} y_{i j}}{y_{i 1}}\right)\right|=\left|\frac{\sum_{j=1}^{J} y_{i j}}{\prod_{j=1}^{J} y_{i j}}\right| .
$$

\section{Appendix C: Gauss program}

In Section 1 we give the Gauss code used in this paper. Section 2 contains an example of the structure of an Excel spreadsheet which is needed as input for the Gauss program. Note the data in this Excel file are artificial.

\section{Gauss code}

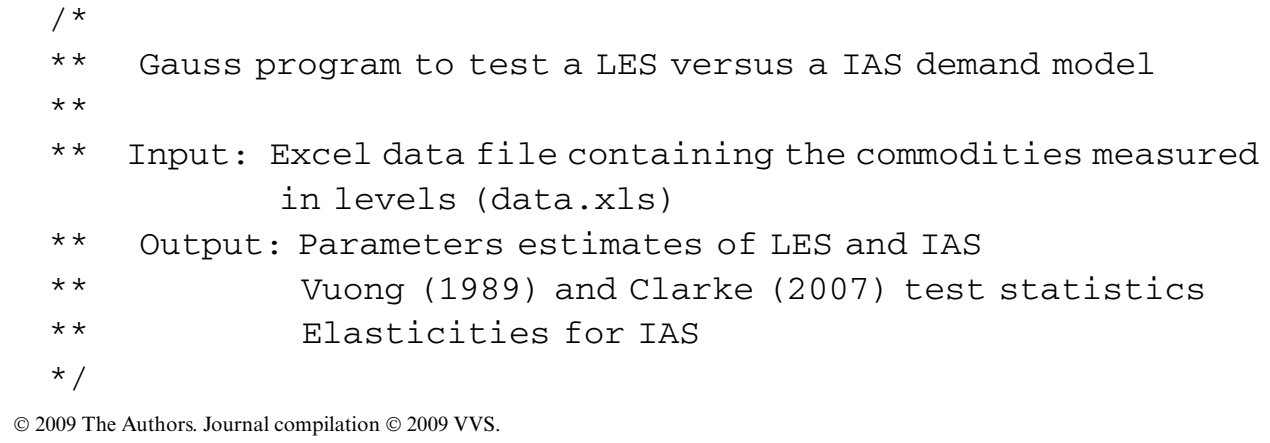


y=spreadsheetreadM("data", "A2:J1001",1); a read data from spreadsheet a

$\mathrm{m}=\operatorname{sumc}\left(\mathrm{Y}^{\prime}\right)$; a compute total expenditures @

format 8,5 ;

output file="lesvias.out" reset;

noc $=\operatorname{cols}(\mathrm{y})$; a determine number of commodities @

noo=rows $(y)$; a determine number of observations a

yle=y $[., 2:$ noc $] ; \quad$ a dependent variables LES a

base $=\mathrm{y}[., 1] ; \quad$ a first commodity is base commodity a

$\mathrm{xle}=$ ones $(\mathrm{noo}, 1) \sim \mathrm{m}$; a regressors LES a

betale $=y l e / x l e$;

a OLS estimator a

resle=yle-xle*betale;

a compute residuals a

sigmale=resle'resle/rows (noo); a MLE covariance matrix residuals @

sele=sqrt (reshape (diag (sigmale . * invpd (xle'xle) ), noc-1,2)) ;

a compute st. errors a

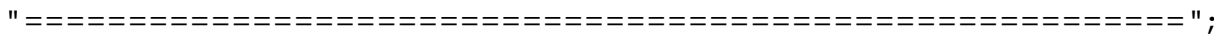

"LES parameters intercepts + standard errors + t-values" ; ;

(betale [1,.]') sele $[., 1]^{\sim}\left(\right.$ betale $[1, .]^{\prime}$./sele $\left.[., 1]\right)$;

"LES marginal budget share parameters + standard errors

+ t-values "; ;

(betale $\left.[2, .]^{\prime}\right)^{\sim}$ sele $[., 2]^{\sim}\left(\right.$ betale $[2, .]^{\prime} . /$ sele $\left.[., 2]\right)$;

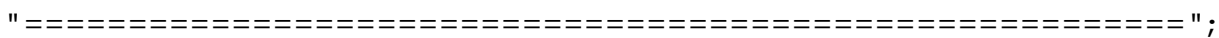

yia $=\ln (y l e)-\ln ($ base); a dependent variables IAS @

xia=ones $(n o o, 1) \sim \ln (\mathrm{m})$; a regressors IAS @

betaia=yia/xia; a OLS estimator a

resia=yia-xia*betaia; a compute residuals a

sigmaia=resia'resia/noo; a MLE covariance matrix a

seia=sqrt (reshape (diag (sigmaia . * invpd (xia'xia)), noc-1,2)) ;

a compute st. errors a

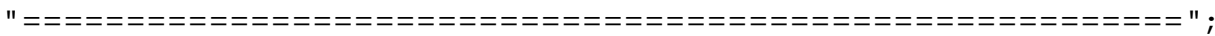

"IAS parameters intercepts + standard errors + t-values "; ;

(betaia [1,..]') $\operatorname{seia}[., 1] \sim\left(\right.$ betaia $[1, .]^{\prime}$./seia [.,1]);

"IAS reaction coefficients + standard errors + t-values" ; ;

(betaia [2,..]') $\operatorname{seia}[., 2] \sim\left(\right.$ betaia $[2, .]^{\prime}$./seia [.,2]);

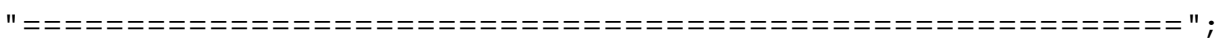

llle=lnpdfmvn (resle,sigmale); a log-likelihood

contributions LES @

llia=lnpdfmvn (resia, sigmaia) $+\ln \left(\operatorname{sumc}\left(y^{\prime}\right)\right)-\operatorname{sumc}\left(\ln \left(y^{\prime}\right)\right)$;

a log-likelihood contr. IAS a

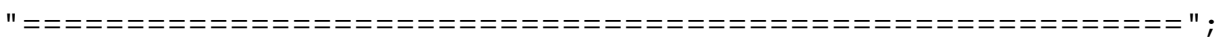

"number of obs" ; ;

(c) 2009 The Authors. Journal compilation (c) 2009 VVS. 
noo;

"number of commodities"; ;

noc;

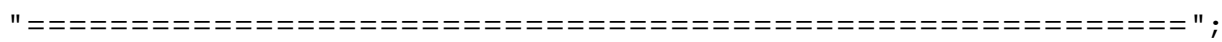

"average log likelihood value LES per observation" ; ; sumc (llle)/noo;

"average log likelihood value IAS in levels per observation" ; ; sumc (llia)/noo;

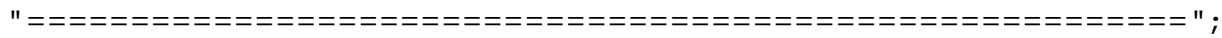

"Clarke (2007) test" ;

"number of times loglikelihood contributions IAS better than LES " ;

clarke=sumc (llia.gt llle);

clarke;

"fraction of loglikelihoods IAS better than LES" ;

clarke/noo;

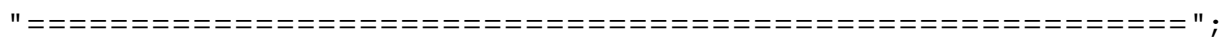

"Vuong (1989) test statistic (positive means IAS better) : " ;

vuong $=($ sumc $(11 i a)-$ sumc $(11 l e)) /$ sqrt $\left(\right.$ meanc $\left((11 i a-11 l e)^{\wedge} 2\right)$

-meanc(liia-llle)^2)/sqrt (noo);

vuong;

"p-value: " ;

cdfnc (vuong);

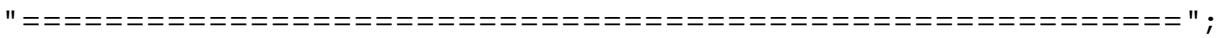

wghts=meanc $(\mathrm{y})$. /meanc $(\mathrm{m})$; a compute budget weights @

elas $=\left(1-\operatorname{sumc}\left(\left(\operatorname{wghts}[2: \text { noc }]^{\prime} .{ }^{*} \text { betaia }[2, .]\right)^{\prime}\right)\right)$

| (1+(betaia [2,.]-sumc ( (wghts [2:noc ] ' * betaia [2,. ] )') )') ; betacov $=\left(\right.$ sigmaia . ${ }^{*}$ invpd(xia'xia)); a compute covariance matrix @

ind=seqa $(2,2$, noc-1); a index to select reaction coefficients a betacov=betacov [ind, ind]; a select relevant covariance matrix a transf $=\left(\operatorname{zeros}(1, \operatorname{noc}-1) \mid\right.$ eye $($ noc-1) $)-\left(\left(0^{\sim}\left(\right.\right.\right.$ wghts $\left.\left.[3: \text { noc }]^{\prime}\right)\right)$

|diagrv(ones (noc-1,1) . * (wghts $\left.[2: \text { noc }]^{\prime}\right)$, zeros $($ noc-1,1))) ; elasse=sqrt (diag (transf*betacov*transf')) ;

"IAS" ;

"Budget weights + elasticities + standard errors" ; ;

wghts $\sim e l a s^{\sim} e l a s s e$;

output off ;

\section{Excel Spreadsheet}

The format of the excel Spreadsheet data.xls is as follows: 


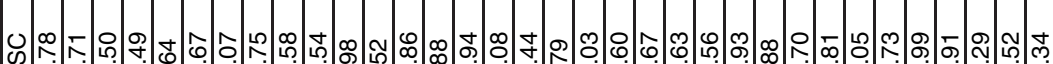

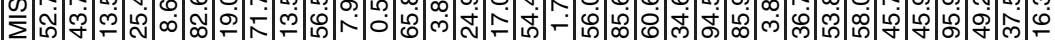

은

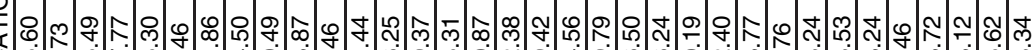
仓ల

แิ

은

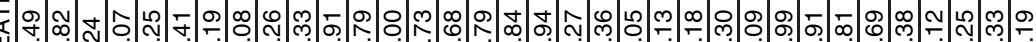
崩 㟧

稀

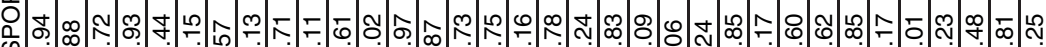

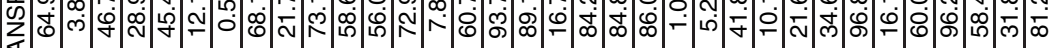
$\stackrel{\nwarrow}{\dddot{r}}$

元 它

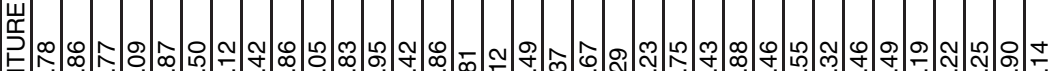

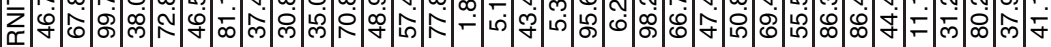
간

至

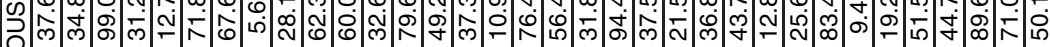
운

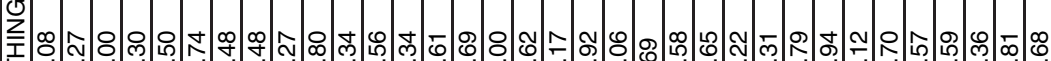
○

o

出

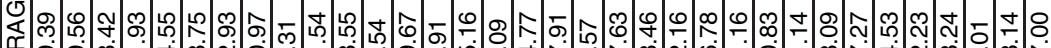
崩 N 岗

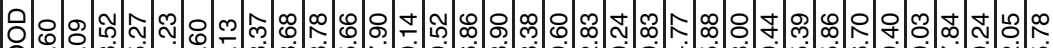
४ ம 


\section{Notes}

1. Documents and discussion papers can be obtained at: http://www.cpb.nl/eng/research/.

2. Calibration needs $J$ equations (VAn Der Mensbrugghe, 2005, p. 91) instead of 1 in case of LES or IAS. As shown in Appendix A of this paper, knowledge of one's own price elasticity leads to identification of all parameters. AIDADS requires the knowledge of all $J$ 's own price elasticities.

3. The specification of Houthakker (1960) reads: $\Sigma_{j=1}^{J} c_{j}^{*}\left(m / p_{j}\right)^{\beta_{j}}$. Using the reparameterization $c_{j}=c_{j}^{*} \beta_{j}$ and subtracting the constant $\Sigma_{j=1}^{J} c_{j} / \beta_{j}$ we arrive at Equation (11). Both specifications represent the same preferences, but the advantage of Equation (11) is that the parameter restrictions can readily be derived, see MurTy (1982) and De BoER et al. (2006), and that the special case $\beta_{j}=0$ is defined to be equal to $\ln \left(m / p_{j}\right)$.

4. In Leser (1941), Somermeyer and Wit (1956) and Somermeyer and Langhout (1972), the reaction coefficients are denoted by $\alpha_{j}\left(=-\beta_{j}\right)$. If all $\beta_{j}=\beta$, IAS reduces to the CES function (ARrow et al., 1961). If, moreover, $\beta=0$, we obtain the Cobb-Douglas function.

5. Hanoch (1975), Deaton and Muellbauer (1980) and Chung (1994) give as restriction $\beta_{j}>0$, excluding the region $-1 \leq \beta_{j}<0$. As a consequence, the existence of inelastic demand and of gross complementarity is, erroneously, excluded.

6. It can be shown that $\phi_{m}=\Sigma_{k=1}^{J} w_{k} \beta_{k}-1>-2$ in view of $\beta_{j} \geq-1$.

\section{References}

Arrow, K. J., H. B. Chenery, B. Minhas and R. M. Solow (1961), Capital-labor substitution and economic efficiency, Review of Economics and Statistics 43, 225-250.

BChIR, M. H., Y. Decreux, J.-L. GuÉrin and S. JeAn (2002), MIRAGE, a computable general equilibrium model for trade policy analysis, Working Paper 2002-17, CEPII, Paris, France.

Blonigen, B. A., J. E. Flynn and K. A. Reinert (1997), Sector-focused general equilibrium modeling, in: J. F. Francois and K. A. Reinert (eds), Applied methods of trade policy analysis: a handbook, Cambridge University Press, Cambridge, UK, pp. 189-230.

Chung, J. W. (1994), Utility and production functions: theory and applications, Blackwell, Oxford, UK.

Clarke, K. A. (2007), A simple distribution-free test for nonnested model selection, Political Analysis 15, 347-363.

Совв, C. W. and P. H. Douglas (1928), A theory of production, American Economic Review, Papers and Proceedings XVIII, 139-165.

Cranfield, J. A. L., P. V. Preckel, J. S. Eales and T. W. Hertel (2000), On the estimation of 'an implicitly additive demand system', Applied Economics 32, 1907-1915.

Deaton, A. S. and J. Muellbauer (1980), Economics and consumer behavior, Cambridge University Press, Cambridge, UK.

De Boer, P. M. C., J. Bröcker, B. S. Jensen and J. Van DaAl (2006), The expenditure system of the CDES indirect utility function, Econometric Institute Report EI 2006-11, Erasmus University Rotterdam (http://hdl.handle.net/1765/7757).

De Bruisn, R., H. Kox and A. Lejour (2008), Economic benefits of an integrated European market for services, Journal of Policy Modelling 30, 301-319.

Dhrymes, P. J. (1978), Mathematics for econometrics, Springer-Verlag, New York.

Don, F. J. H. and J. P. Verbruggen (2006), Models and methods for economic policy: 60 years of evolution at CPB, Statistica Neerlandica 60, 145-170.

Engel, E. (1857), Die Productions- und Consumptionsverhältnisse des Königreichs Sachsen, Zeitschrift des Statistisches Bureaus des Königlich Sächsischen Ministerium des Innern, reprinted in: Bulletin of the International Statistical Institute (1895), 9, 1-54.

GeARY, R. C. (1949-1950), A note on 'A constant utility index of the cost of living', Review of Economic Studies 18, 65-66. 
Hanoch G. (1975), Production and demand models with direct or indirect implicit additivity, Econometrica 43, 395-419.

HouthaKker, H. S. (1960), Additive preferences, Econometrica 28, 244-257.

KLeIN, L. R. and H. Rubin (1948-1949), A constant utility index of the cost of living, Review of Economic Studies 15, 84-87.

Lejour, A., P. Veenendaal, G. Verwey and N. Van Leeuwen (2006), WorldScan: a model for international economic policy analysis, CPB Document 111, CPB Netherlands Bureau for Economic Policy Analysis, The Hague, the Netherlands.

Lejour, A., H. Rojas-Romagosa and G. Verweij (2008), Opening services markets within Europe; modelling foreign establishments in a CGE framework, Economic Modelling 25, $1022-1039$.

LeSER, C. E. V. (1941), Family budget data and price-elasticities of demand, Review of Economic Studies 9, 40-57.

MurTy, K. N. (1982), Theoretical restrictions on the parameters of indirect addilog demand equations-a comment, Econometrica 50, 225-227.

PECS (2005), Palestinian Central Bureau of Statistics, Ramallah, Palestine.

Reimer, J. J. and T. W. Hertel (2004), Estimation of international demand behaviour for use with input-output based data, Economic Systems Research 16, 347-366.

Rimmer, M. T. and A. A. Powell (1996), An implicitly additive demand system, Applied Economics 28, 1613-1622.

Samuelson, P. A. (1948), Some implications of linearity, Review of Economic Studies 30, 88-90.

Schwabe, H. (1868), Das Verhältnis von Miethe und Einkommen in Berlin, in: Berlin und seine Entwickelung- Gemeinde-Kalender und städtisches Jahrbuch für 1868, Zweiter Jahrgang, Berlin, Germany, 264-266.

Somermeyer, W. H. and A. Langhout (1972), Shapes of Engel curves and demand curves: implications of the expenditure model applied to Dutch data, European Economic Review 3, 351-386.

Somermeyer, W. H. and J. W. W. A. Wit (1956), Een verdeelmodel (an allocation model), Report M14, Statistics Netherlands, Voorburg.

STONE, R. (1954), Linear expenditure system and demand analysis: an application to the British pattern of demand, Economic Journal 64, 511-532.

Tinbergen, J. (1942), Professor Douglas' production function, Revue de l'Institut International de Statistique 10, 37-48.

VAn der Mensbrugghe, D. (2005), Linkage technical reference document, version 6.0, The World Bank, Washington, DC.

VARIAN, H. R. (1992), Microeconomic analysis, 3rd edition, Norton, New York.

VeenendaAl, P. and T. MAnders (2008), Border tax adjustment and the EU-ETS, a quantitative assessment, CPB Document 171, CPB Netherlands Bureau for Economic Policy Analysis, The Hague, The Netherlands.

VUONG, Q. H. (1989), Likelihood ratio tests for model selection and non-nested hypotheses, Econometrica 57, 307-333.

Received: April 2009. Revised: April 2009 